\title{
The first case of cutaneous phaeohyphomycosis caused by Bipolaris spicifera in Northern China: A case report
}

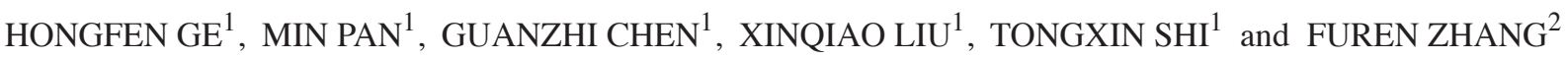 \\ ${ }^{1}$ Department of Dermatology, Qingdao University Affiliated Hospital, Qingdao University, \\ Qingdao, Shandong 266003; ${ }^{2}$ Shandong Provincial Institute of Dermatology and Venereology, \\ Shandong Academy of Medical Sciences, Jinan, Shandong 250022, P.R. China
}

Received July 17, 2015; Accepted September 9, 2016

DOI: $10.3892 /$ etm.2017.4765

\begin{abstract}
Phaeohyphomycosis (PHM) is a term used to describe any fungus presenting in tissues with pseudohyphae, hyphae, brown yeast-like cells or a combination of these forms. Sinusitis and skin infections are the most common presentation of subcutaneous PHM caused by the fungus Bipolaris spicifera. However, the majority of cases have so far been encountered in tropical climatic zones. The present study documents a case of subcutaneous PHM caused by infection with Bipolaris spicifera in a 56-year-old Chinese man, who presented with plaque papillomatosis on the left foot. The organism isolated from the lesion scar and tissue was identified as Bipolaris spicifera by its morphology, histopathology and DNA sequencing. The patient was successfully treated with itraconazole and terbinafine.
\end{abstract}

\section{Introduction}

Phaeohyphomycosis (PHM) refers to phaeoid fungal infections with specific structures including pseudohyphae, hyphae and brown yeast-like cells seen in tissue samples $(1,2)$. Currently, there are at least 60 genera and 109 species that can cause PHM. The most frequent etiologic agents are Exophiala spinifera, Wangiella spinifera, Phialophora spinifera and Bipolaris spinifera (3).

PHM-inducing agents are widely distributed around the world; however, they are more frequently observed in tropical and subtropical climates (4). PHM occurs in immunocompromised and immunocompetent individuals, although organ transplantation, cancer, leukemia, prolonged hospitalization and corticosteroid therapy are predisposing factors $(5,6)$. Cases of PHM have been reported in different regions such as the

Correspondence to: Dr Hongfen Ge, Department of Dermatology, Qingdao University Affiliated Hospital, Qingdao University, 16 Jiangsu Road, Qingdao, Shandong 266003, P.R. China

E-mail: 18661807818@163.com

Key words: cutaneous phaeohyphomycosis, Bipolaris spicifera, Northern China
Caribbean islands, parts of South America, Africa, the Indian subcontinent, Southeast Asia, and the West Pacific Islands (3). The incidence in patients with solid organ transplantation is $\sim 9 \%$ (5).

PHM may be categorized as either superficial, cutaneous and corneal, subcutaneous, and systemic PHM (5). Bipolaris spicifera is typically associated with subcutaneous PHM and symptoms such as sinusitis and skin infections $(7,8)$. The majority of cases so far have been encountered in tropical climatic zones (5). The present case, however, exhibits the first case of subcutaneous phaeohyphomycosis caused by Bipolaris spicifera in Northern China, in an area with a subtropical climate.

\section{Case report}

A 56-year-old Chinese male presenting with papular nodules and plaque papillomatosis on the left foot was admitted into the Department of Dermatology, Qingdao University Affiliated Hospital (Qingdao, China) in June 2014. Initial onset was characterized by the appearance of scattered papules and nodules on the dorsum of the left foot 10 years previously, without clinical symptoms. The lesion converged gradually, formed a granuloma-like lesion and spread from the hallux to the dorsum of the foot and the second, third and fourth toes, with occasional co-presentation of bloody pus. The patient also had a prior medical history of rheumatoid arthritis for one year prior to this onset. The patient was a farmer living in Shandong Province, had never traveled outside the province and had never experienced any traumatic injury or animal bites to the left foot. In addition, the patient did not receive any treatment prior to admission. Written informed consent was obtained from the patient for inclusion in the current study.

Immune function tests revealed that total T-cells [cluster of differentiation (CD) 3] were slightly decreased $(60.40 \%$; normal value range, 61.1-77.0\%), whereas B-cells (CD19) were slightly increased (18.30\%; normal value range, 7.3-18.2\%). Results of other examinations including routine blood test, and liver and kidney function tests were unremarkable. The patient had large fusion plaques on the first to fourth toes and the dorsal skin of the left foot. The fusion plaques had irregular and uneven surfaces, a granularly rough and wart-like appearance, among which black-dotted scabs were observed. A small 


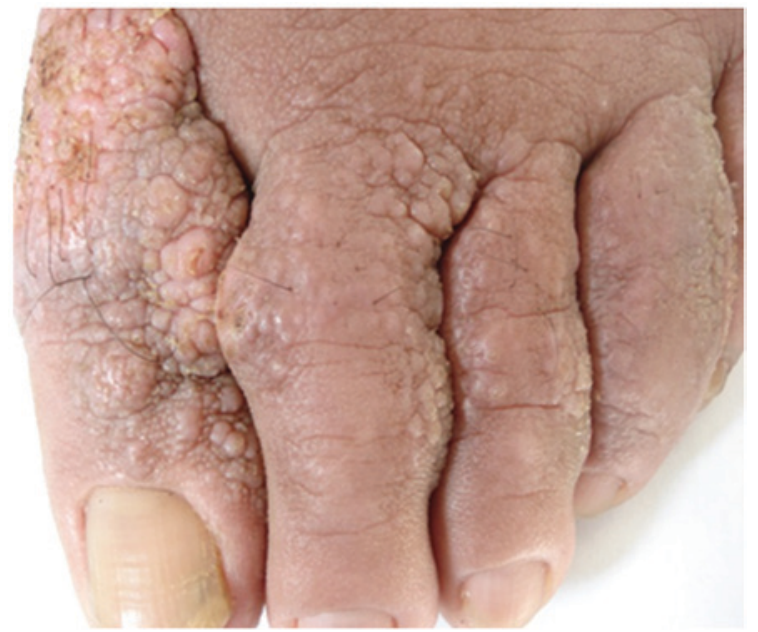

Figure 1. Granuloma-like mass with black-dotted scabs.

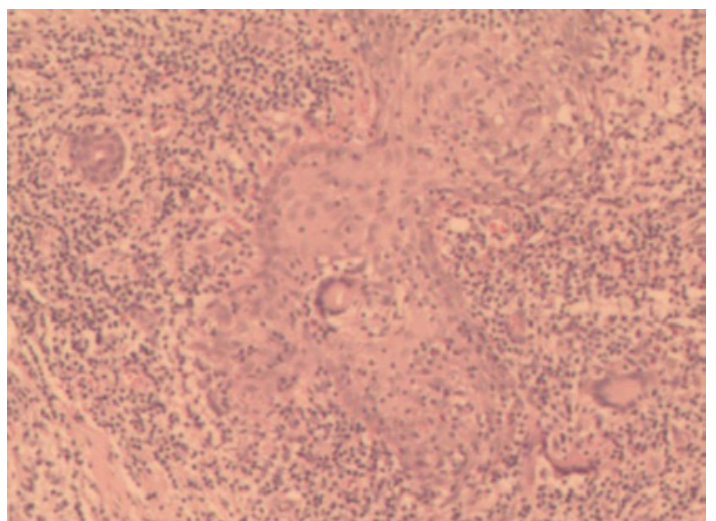

Figure 2. Granulomatous reactions with lymphocytes, multinucleated cells and macrophage infiltration (original magnification, $\mathrm{x} 40$; haematoxylin and eosin stain).

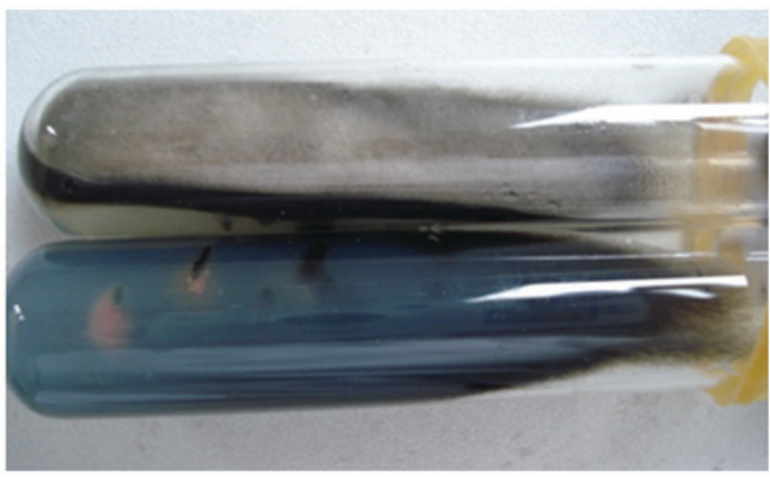

Figure 3. Colony on Sabouraud dextrose agar following 4 days of incubation. The colony surface is brownish.

amount of pus oozed following compression. Dark red skin surrounded the infiltration (Fig. 1).

Sheets of lymphocytes, multinucleated cells, macrophages and other cellular inflammatory infiltrates suggestive of non-caseating granulomatous reactions were observed following wedge biopsy of the eruption. The biopsy sample was stained with periodic acid-Schiff, and hematoxylin and eosin (Fig. 2). Eruption scrapings were subsequently collected

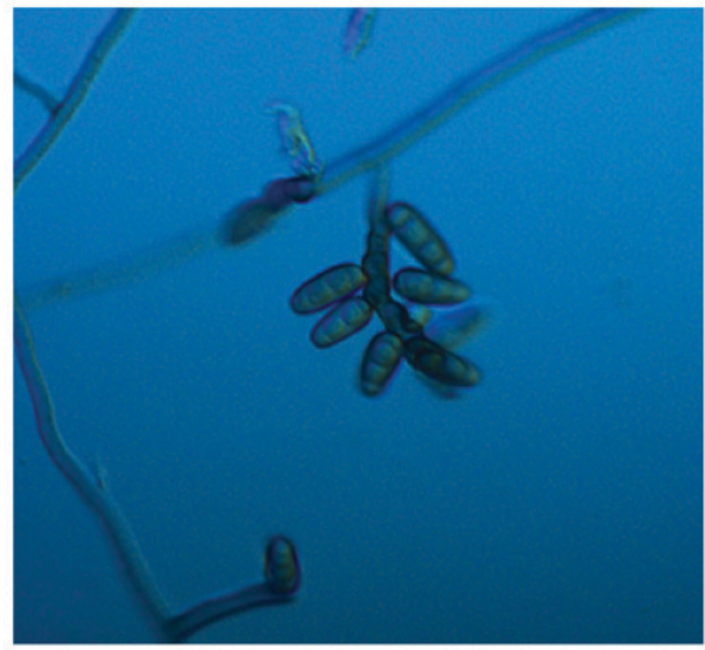

Figure 4. Brown septate hyphae with darkly pigmented three and four septate cylindrical conidia.

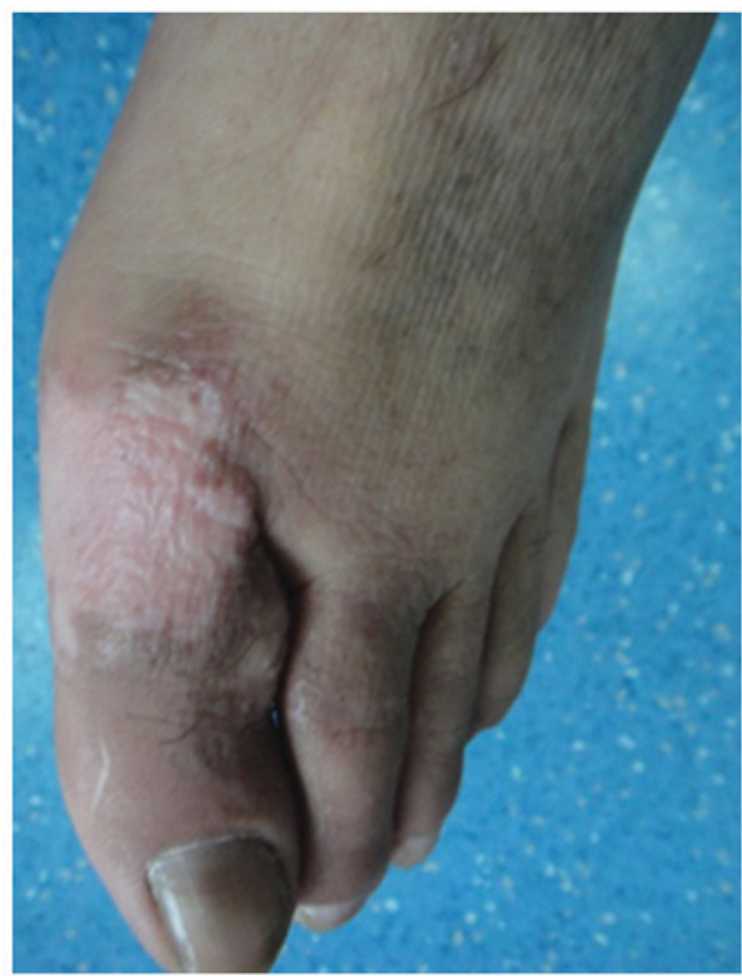

Figure 5. Mass recovery on the left toe following treatment.

and subjected to light microscopy. Potassium hydroxide preparation tested negative for fungal structures. Pure growth of white mycelial colony was obtained on Sabouraud dextrose agar after 4 days incubation at $25^{\circ} \mathrm{C}$. Following 10 days of further incubation at $25^{\circ} \mathrm{C}$, the colony changed color to gray black with black pigmentation on reverse. Colonies were brown in color and fast growing (Fig. 3).

Microscopy revealed septate pigmented hyphae and unbranched zigzagged conidiophores with thick-walled, darkly pigmented cylindrical conidia, which were predominantly three septate and sometimes four septate. Thus, the fungus was subsequently identified as Bipolaris spicifera (Figs. 4 and 5). To confirm this, fungal DNA was extracted 
from the isolate cultured on potato glucose agar $\left(28^{\circ} \mathrm{C}\right.$ for 7 days). Briefly, DNA was extracted using a commercial kit (QIAamp DNA Mini Kit; Qiagen, Inc., Valencia, CA, USA) following incubation, according to the manufacturer's instructions. The concentration and purity of the DNA preparations was determined using a NanoDrop 1000 spectrophotometer (Thermo Fisher Scientific, Inc., Waltham, MA, USA) with absorbance at 260 and $280 \mathrm{~nm}$. A segment of ribosomal DNA (rDNA) was amplified by PCR using the fungal oligonucleotide primers BMB-CR (5'-GTACACACCGCCCGTCG-3') and ITS4 (5'-TCCTCCGCTTATTGATATGC-3'). Amplification was performed in a $25 \mu 1$ reaction mixture containing $100 \mathrm{ng}$ genomic DNA, $20 \mathrm{pmol} / 1$ each primer, $10 \mathrm{mM}$ each dNTP (Nanjing KeyGen Biotech Co., Ltd., Nanjing, China), $2.5 \mu 1$ 10X PCR buffer (Nanjing KeyGen Biotech Co., Ltd.), $1.5 \mathrm{mmol} / 1 \mathrm{MgCl}_{2}$ and 1 unit Taq DNA polymerase (Takara Bio, Inc., Otsu, Japan), with the following cycling conditions: $95^{\circ} \mathrm{C}$ for $5 \mathrm{~min}$, followed by 30 cycles of $95^{\circ} \mathrm{C}$ for $30 \mathrm{sec}$, $58^{\circ} \mathrm{C}$ for $30 \mathrm{sec}$, and $72^{\circ} \mathrm{C}$ for $1 \mathrm{~min}$, with a final extension at $72^{\circ} \mathrm{C}$ for $10 \mathrm{~min}$. Direct sequencing of the PCR products was performed. The sequence was compared with entries in GenBank by BLAST analysis (www.ncbi.nlm.nih.gov/blast/) and displayed a $99.9 \%$ match with Bipolaris spicifera.

The patient was diagnosed with PHM and treated with $400 \mathrm{mg} /$ day itraconazole (Xi'an Janssen Pharmaceutical Co., Ltd., Xi'an, China) and 0.25 g/day terbinafine (Qilu Pharmaceutical Co., Ltd., Jinan, China) for 3 months. Following 8 weeks of treatment, complete resolution had been achieved (Fig. 5) and no recurrence was observed in the 6-month follow-up period.

\section{Discussion}

PHM was first defined by Ajello et al (1) in 1974 and refers to a group of mycotic infections caused by dematiaceous (darkly pigmented) fungi containing melanin in their cell walls. Clinical manifestations of PHM vary between subcutaneous and superficial subcutaneous to systemic (5). Subcutaneous infections occur primarily on extremities, including the ankles, knees, wrists and fingers (9). The major etiological agents are Curvularia, Exophiala, Exserohilum, Chaetomium, Phoma and Bipolaris (5). The genus Bipolaris encompasses a number of species, including B. australiensis, B. hawaiiensis and B. spicifera. In the literature, Bipolaris spicifera has been implicated as a cause of diseases in animals and humans (10).

As well as subcutaneous and cutaneous PHM, Bipolaris may cause fungal sinusitis, skin infections, fungal keratitis and eye abscesses. Furthermore, it may lead to infection of the peritoneum, bronchus and other debilitating conditions, including meningitis and disseminated infections (10-18). da Cunha et al (8) identified that Bipolaris spicifera was one of the major pathogenic species, accounting for $67.3 \%$ in all 104 clinical samples morphologically compatible with Bipolaris. Sinusitis was the most common infection, accounting for $30.7 \%$ and skin infections were the second, accounting for $19.2 \%$ of cases (8). To the best of our knowledge, the present study documents the first reported case of subcutaneous PHM caused by Bipolaris spicifera in Northern China.
Infection with Bipolaris spicifera occurs due to patients coming into contact with fungal material from contaminated soil and plants, usually by traumatic implantation. A number of patients with PHM have no obvious exposure history. However, the patient in the current study was a farmer, routinely coming into contact with soil and plants. Therefore the probable mode of transmission of the disease in the present case was traumatic inoculation, although the patient was unable to recall a definite traumatic incident.

The majority of patients with PHM are immunocompromized $(3,19)$. The present patient, who had a previous history of rheumatoid arthritis and slightly abnormal $\mathrm{T}$ and B cell counts, was considered as having an immune dysfunction. However, immunocompromization is not a necessary condition for PHM to occur (20). The etiological agent was identified by morphological characteristics and the pattern of sporulation, as molecular diagnosis. Fungal microscopy and histopathology failed to identify the species of the fungi; however, the mixed pyogenic granuloma reaction and DNA sequences were consistent with the pathological features of PHM. Meanwhile, the patient recovered following antifungal therapy, with complete regression of clinical manifestation, which also confirmed the presence of a fungal infection from another source. Thus, the final diagnosis of the patient was PHM caused by Bipolaris spicifera.

Antifungal agents, including flucytosine and itraconazole, appear to be effective treatments for patients with subcutaneous phaeohyphomycosis caused by Bipolaris spicifera (8). Surgical excision has been widely used to treat subcutaneous PHM (5). However, there is currently insufficient clinical data and no standard antifungal regimen to treat subcutaneous PHM caused by Bipolaris spicifera.

In conclusion, the present study reports a rare case of subcutaneous PHM caused by Bipolaris spicifera in a Chinese man. To our knowledge, this is the first reported case of Bipolaris spicifera-induced PHM from China.

\section{Acknowledgements}

The present study was supported by the Department of Science and Technology of Shandong Province (grant no. 2011YD18044).

\section{References}

1. Ajello L, Georg LK, Steigbigel RT and Wang CJ: A case of phaeohyphomycosis caused by a new species of Phialophora. Mycologia 66: 490-498, 1974.

2. de Hoog GS: Significance of fungal evolution for the understanding of their pathogenicity, illustrated with agents of phaeohyphomycosis. Mycoses 40 (Suppl 2): S5-S8, 1997.

3. Brandt ME and Warnock DW: Epidemiology, clinical manifestations, and therapy of infections caused by dematiaceous fungi. J Chemother 15 (Suppl 2): S36-S47, 2003.

4. Adam RD, Paquin ML, Petersen EA, Saubolle MA, Rinaldi MG, Corcoran JG, Galgiani JN and Sobonya RE: Phaeohyphomycosis caused by the fungal genera Bipolaris and Exserohilum. A report of 9 cases and review of the literature. Medicine (Baltimore) 65: 203-217, 1986.

5. Isa-Isa R, García C, Isa M and Arenas R: Subcutaneous phaeohyphomycosis (mycotic cyst). Clin Dermatol 30: 425-431, 2012.

6. Matsumoto T, Ajello L, Matsuda T, Szaniszlo PJ and Walsh TJ: Developments in hyalohyphomycosis and phaeohyphomycosis. J Med Vet Mycol 32 (Suppl 1): S329-S349, 1994. 
7. Buzina W, Braun H, Schimpl K and Stammberger H: Bipolaris spicifera causes fungus balls of the sinuses and triggers polypoid chronic rhinosinusitis in an immunocompetent patient. J Clin Microbiol 41: 4885-4887, 2003.

8. da Cunha KC, Sutton DA, Fothergill AW, Cano J, Gené J, Madrid H, De Hoog S, Crous PW and Guarro J: Diversity of Bipolaris species in clinical samples in the United States and their antifungal susceptibility profiles. J Clin Microbiol 50: 4061-4066, 2012.

9. Rinaldi MG: Phaeohyphomycosis. Dermatol Clin 14: 147-153, 1996.

10. Saha R and Das S: Bipolaris keratomycosis. Mycoses 48: 453-455, 2005.

11. Bilu D, Movahedi-Lankarani S, Kazin RA, Shields C and Moresi M: Cutaneous Bipolaris infection in a neutropenic patient with acute lymphoblastic leukemia. J Cutan Med Surg 8: 446-449, 2004.

12. Chowdhary A, Randhawa HS, Singh V, Khan ZU, Ahmad S, Kathuria S,Roy P,KhannaGand Chandra J: Bipolarishawaiiensis as etiologic agent of allergic bronchopulmonary mycosis: First case in a paediatric patient. Med Mycol 49: 760-765, 2011.

13. Karim M, Sheikh H, Alam M and Sheikh Y: Disseminated Bipolaris infection in an asthmatic patient: Case report. Clin Infect Dis 17: 248-253, 1993.
14. Kobayashi H, Sano A, Aragane N, Fukuoka M, Tanaka M, Kawaura F, Fukuno Y, Matsuishi E and Hayashi S: Disseminated infection by Bipolaris spicifera in an immunocompetent subject. Med Mycol 46: 361-365, 2008.

15. Latham RH: Bipolaris spicifera meningitis complicating a neurosurgerical procedure. Scand J Infect Dis 32: 102-103, 2000.

16. Teran CG, Downes K and Medows M: Fatal Bipolaris spicifera infection in an immunosuppressed child. BMJ Case Rep 2014: pii: bcr2013009703, 2014

17. Robb CW, Malouf PJ and Rapini RP: Four cases of dermatomycosis: Superficial cutaneous infection by Alternaria or Bipolaris. Cutis 72: 313-316, 319, 2003.

18. Bava AJ, Fayad A, Céspedes C and Sandoval M: Fungal peritonitis caused by Bipolaris spicifera. Med Mycol 41: 529-531, 2003.

19. Clancy CJ, Wingard JR and Hong Nguyen M: Subcutaneous phaeohyphomycosis in transplant recipients: Review of the literature and demonstration of in vitro synergy between antifungal agents. Med Mycol 38: 169-175, 2000.

20. Frank T, Esquenazi Y, Nigo M, Wanger A, Portnoy B and Shepard S: Disseminated phaeohyphoycosis with brain abscess and biliary invasion due to Bipolaris spp. in an immunocompetent patient. Ann Clin Lab Sci 46: 439-442, 2016. 